\title{
Die Bedeutung des Elbe-Ästuars für die Abwasserbe- lastung der südlichen Nordsee in bakteriologischer Sicht
}

\author{
Gerhard RHEINHEIMER \\ Institut für Meereskunde der Universität Kiel, Kiel
}

\begin{abstract}
The importance of the Elbe estuary for polluting the southern North Sea from the bacteriological point of view. The Elbe river and its affluents are polluted by wastes and sewages. Consequently, nutrient concentrations as well as bacterial numbers are relatively high, and the bacteria contanination of the Elbe estuary is influencing the bacteria distribution of the North Sea near Helgoland. The composition of the microflora is changing in the saline zones of the Elbe estuary; freshwater representatives and sewage forms are replaced by halophilic marine bacteria. These changes in the bacterial population are influenced by water temperature - increasing temperatures cause an acceleration. The change of the bacterial flora is also responsible for the retardation of the rate of self-purification in polluted brackish and seawater. The decrease of bacterial activity at low temperatures may cause an increase in the concentration of decomposible pollutants in coastal waters during the winter.
\end{abstract}

\section{EINLEITUNG}

Der Elbe und ihren Nebenflüssen werden an zahlreichen Orten städtische und industrielle Abwässer zugeführt und damit auch große Mengen von Bakterien und Nährstoffen. Von diesen gelangt ein Teil schließlich in die Nordsee und beeinflußt vor allem in der Deutschen Bucht das gesamte Lebensgeschehen. Untersuchungen von Gunkel (1963) zeigten, daß hier die Bakterienverteilung durch die großen Flüsse Elbe, Weser und Ems geprägt wird, und es läßt sich eine Beziehung zwischen dem Bakteriengehalt des Elbe-Astuars und dem der Nordsee vor Helgoland feststellen. So fand Gunkel (1964), daß dem von Rheinhermer (1964a, b) im Februar und März 1963 in der Elbe beobachteten Keimzahlmaximum ein solches in der Nordsee bei Helgoland im April und Mai folgte. Man kann daraus auf einen engen Zusammenhang $z$ wischen dem Bakteriengehalt der Elbe und eines Teiles der südlichen Nordsee schließen. Außerdem wirkt sich die Wasserführung der Elbe auf die Höhe des Salzgehaltes und die Zusammensetzung der Bakterienflora in der Deutschen Bucht aus. Es soll nun im folgenden einiges über den Einfluß der Abwasserbelastung der unteren Elbe auf die bakteriologischen Verhältnisse in der südlichen Nordsee berichtet werden. 


\section{ERGEBNISSE UND DISKUSSION}

Während die obere und die mittlere Elbe großenteils durch städtische und industrielle Abwässer sehr verschmutzt sind, ist der untere Abschnitt des Stromes weniger stark verunreinigt. Auf der $150 \mathrm{~km}$ langen Flußstrecke zwischen der Zonengrenze bei Schnackenburg und Hamburg kommt es zu einer deutlichen Selbstreinigung des Flusses, da hier die Abwassereinleitungen infolge des Fehlens von größeren Städten und

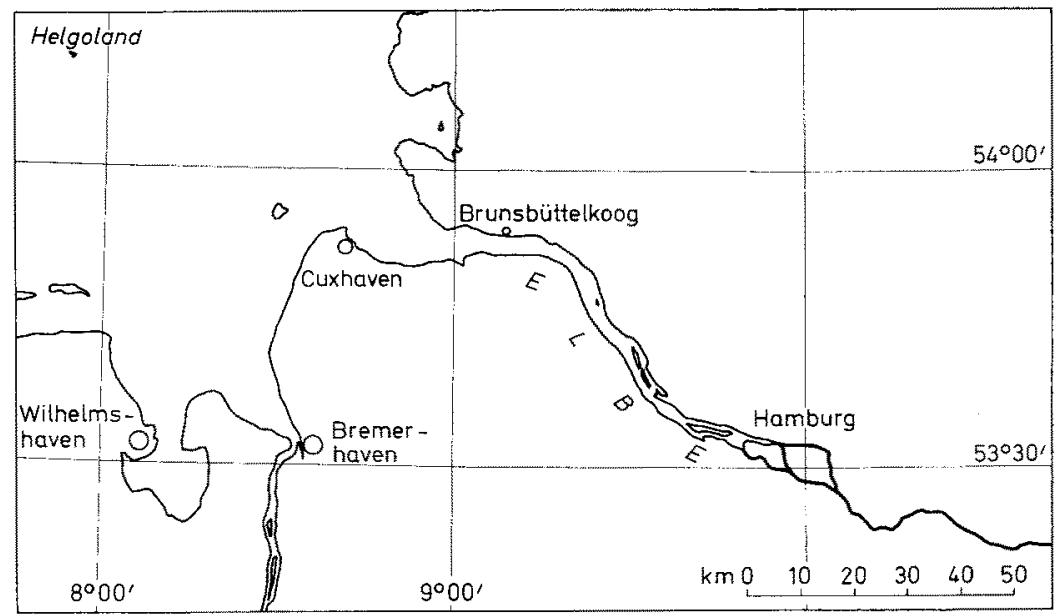

Abb. 1: Skizze des Elbe-Aistuars

Industrieanlagen gering sind. Das zeigt sich in der Abnahme der Gesamtkeim- und Colizahlen sowie der Sauerstoffzehrung, der Sauerstoffsättigung und des Kaliumpermanganat-Verbrauches. Erst im Bereich der Stadt Hamburg erfolgt dann wieder eine stärkere Verschmutzung der Elbe, die durch den Wiederanstieg dieser Werte deutlich wird. Seit der Inbetriebnahme des Hauptklärwerkes Köhlbrandhöft ist dieser Anstieg jedoch nicht mehr so groß wie in früheren Jahren. Unterhalb von HamburgBlankenese läßt sich dann ein abermaliger Rückgang des Gehaltes an Bakterien und Schmutzstoffen beobachten (Abb. 1 und 2). Aber auch dieser Abschnitt des Stromes erfährt immer noch eine erhebliche Belastung durch einige stark verschmutzte Nebenflïsse wie Krückau, Pinnau, Stör und Schwinge (Lucht 1964, Rheinhermer 1965).

Im Brackwasserbereich unterhalb von Glückstadt (vgl. CASPERs 1959) kommt es dann zu einer Umstellung der Bakterienpopulation in der Weise, daß die halotoleranten und vor allem die halophilen Bakterien immer mehr zunehmen, und es läßt sich hier eine deutliche Beziehung zwischen der Höhe des Salzgehaltes und den Anteilen dieser beiden Bakteriengruppen beobachten. Das kann sowohl bei Profiluntersuchungen, z. B. in dem Abschnitt zwischen Altenbruch und der Störmündung, festgestellt werden (Abb. 3) als auch auf Dauerstationen im Brackwasserbereich (Abb. 4). In jedem Falle nimmt mit zunehmendem Salzgehalt des Wassers der Anteil der nur auf Meerwassermedien wachsenden Bakterien zu. Es handelt sich dabei zunächst vor allem um Brack- 
wasserbakterien, die bei Salzgehalten $z$ wischen 5 und $20 \%$ am besten gedeihen. Diese Umstellung der Bakterienpopulation nimmt dann in der Außenelbe ihren Fortgang, wobei die Süßwasser- und schließlich auch die Brackwasserbakterien mehr und mehr durch halophile Meeresbakterien ersetzt werden, die sich bei Salzgehalten von 20 bis $40 \%$ optimal entwickeln. Es werden also in die eigentliche Nordsee nur noch verhältnismäßig wenige Süß- und Abwasserbakterien aus der Elbe gelangen. Die meisten von

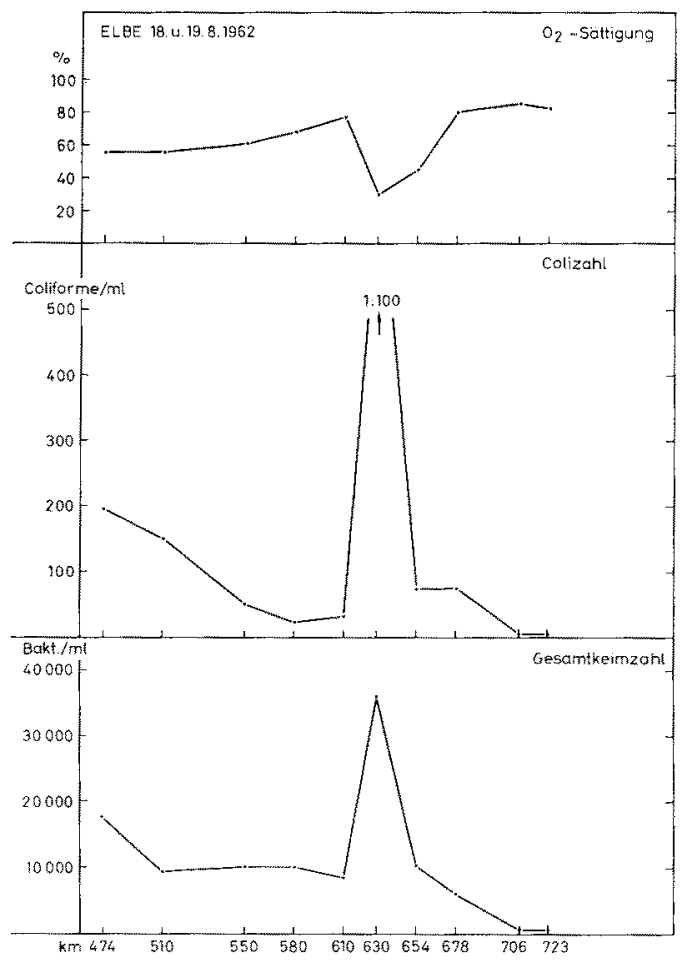

Abb. 2: Sauerstoffsättigung, Colizahl und Gesamtkeimzahl des Elbewassers zwischen Schnackenburg und Cuxhaven am 18. und 19. August 1962

ihnen gehen schon im Brackwasserbereich des Elbe-Astuars zugrunde, in dem sie infolge der Tidebewegungen relativ lange verweilen. In der Nordsee bei Helgoland beträgt nach Gunkel (mündliche Mitteilung) der Anteil der auf Süßwassermedien wachsenden Bakterien im Durchschnitt nur etwa 10\% der Gesamtkeimzahl. Auch WEYLAND (1967) fand auf einem Schnitt von Bremerhaven nach Helgoland bei der überwiegenden Mehrzahl der untersuchten Wasserproben nur wenige Prozent „Süßwasserbakterien“.

Wie Untersuchungen in der westlichen Ostsee und deren Förden zeigen konnten, erfolgt die Umstellung von Bakterienpopulationen aus Süßwasser, Abwasser und aus dem Erdboden auf marine Populationen hier sehr rasch (Rhernhermer 1966). So ist trotz der vielfältigen Landeinflüsse in der Kieler Bucht der Anteil der auf Süßwassermedien wachsenden Bakterien erstaunlich gering. Er beträgt meist 5 bis $10 \%$ der 
Gesamtkeimzahlen auf mit Meerwasser hergestelltem ZoBell-Agar (2216E) und erreicht nur selten einmal mehr als $20 \%$. Selbst in der verhältnismäßig stark belasteten Kieler Förde liegt der Anteil der Süßwasser- und Abwasserbakterien selten über $30 \%$ (Abb. 5). In der Regel ist der Anteil dieser Bakterien in der kalten Jahreszeit größer als in den Sommermonaten. Bei sommerlichen Wassertemperaturen von 15 bis $20^{\circ} \mathrm{C}$

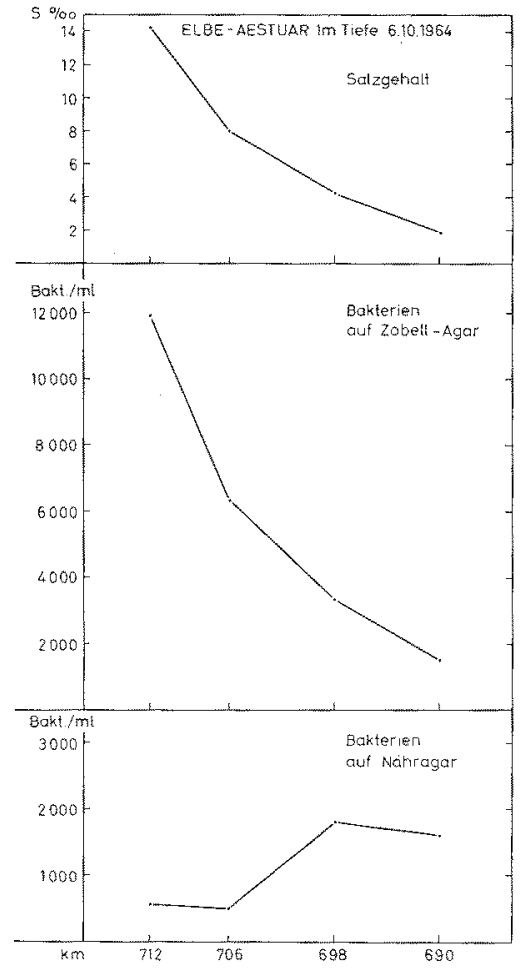

Abb. 3: Salzgehalt, Bakterienzahl auf Meerwassermedium (ZoBell-Agar) und auf Süßwassermedium (Nähragar) im Elbe-Ästuar zwischen Altenbruch (km 712) und St. Margarethen ( $\mathrm{km}$ 690). Mit abnehmendem Salzgehalt geht die Zahl der "Meeresbakterien" zurück und die der "Süßwasserbakterien" steigt an

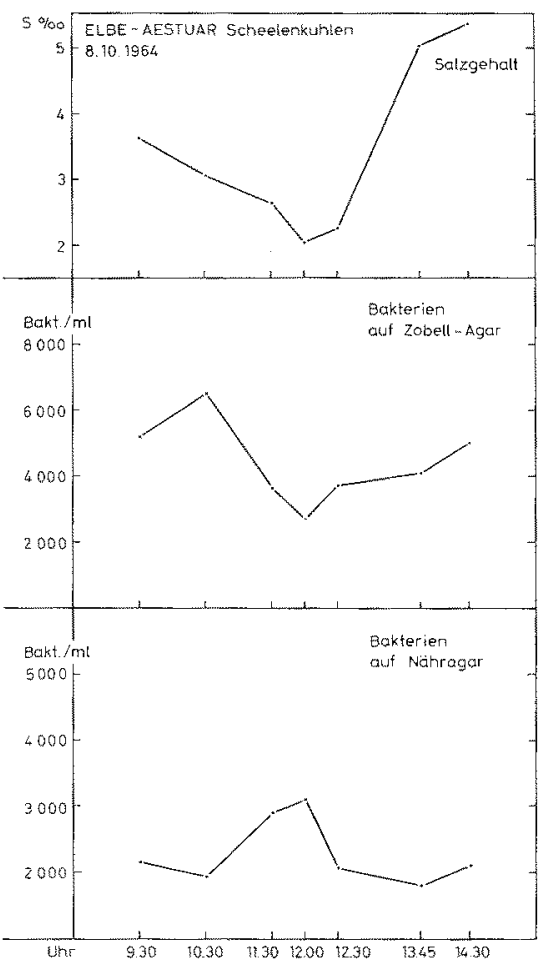

Abb. 4: Anderung von Salzgehalt, Bakterienzahl auf Meerwassermedium (ZoBell-Agar) und auf Süßwassermedium (Nähragar) in Abhängigkeit von der Tide bei der Station Scheelenkuhlen am 8. Oktober 1964 von 9.30 bis 14.30 Uhr. Zur Zeit des Salzgehaltsminimums ist die Zahl der "Meeresbakterien am geringsten und die der "SußBwasserbakterien " am höchsten

erfolgt die Umstellung der Bakterienflora beträchtlich schneller als bei Temperaturen unter $10^{\circ} \mathrm{C}$. Auch ändert sich in Abhängigkeit von der Jahreszeit die artenmäßige Zusammensetzung der marinen Bakterienflora.

Der direkte Einfluß der von der Elbe aufgenommenen Abwässer durch die darin enthaltenen Bakterien auf die Bakterienpopulationen der Nordsee ist also nur verhältnismäßig gering. Sehr beträchtlich ist aber der indirekte Einfluß durch die mitgeführten organischen Nährstoffe. Sie ermöglichen ein vergleichsweise üppiges Wachstum 
von vorwiegend marinen Bakterien, so daß im Einflußbereich der Flußmündungen regelmäßig hohe Gesamtkeimzahlen zu beobachten sind, die 1 bis 2 Zehnerpotenzen über denen der offenen Nordsee liegen (vgl. Gunkel 1963). Die eingangs erwähnten Zusammenhänge zwischen dem Bakteriengehalt der Elbe und dem der Nordsee sind ebenfalls indirekter Natur. Denn auch in diesem Falle hatten wir es in der Nordsee mit anderen Bakterien als in der Elbe zu tun. Aber das erhöhte Nährstoffangebot bewirkte hier wie da eine entsprechend verstärkte Bakterienentwicklung und damit entsprechend hohe Gesamtkeimzahlen.

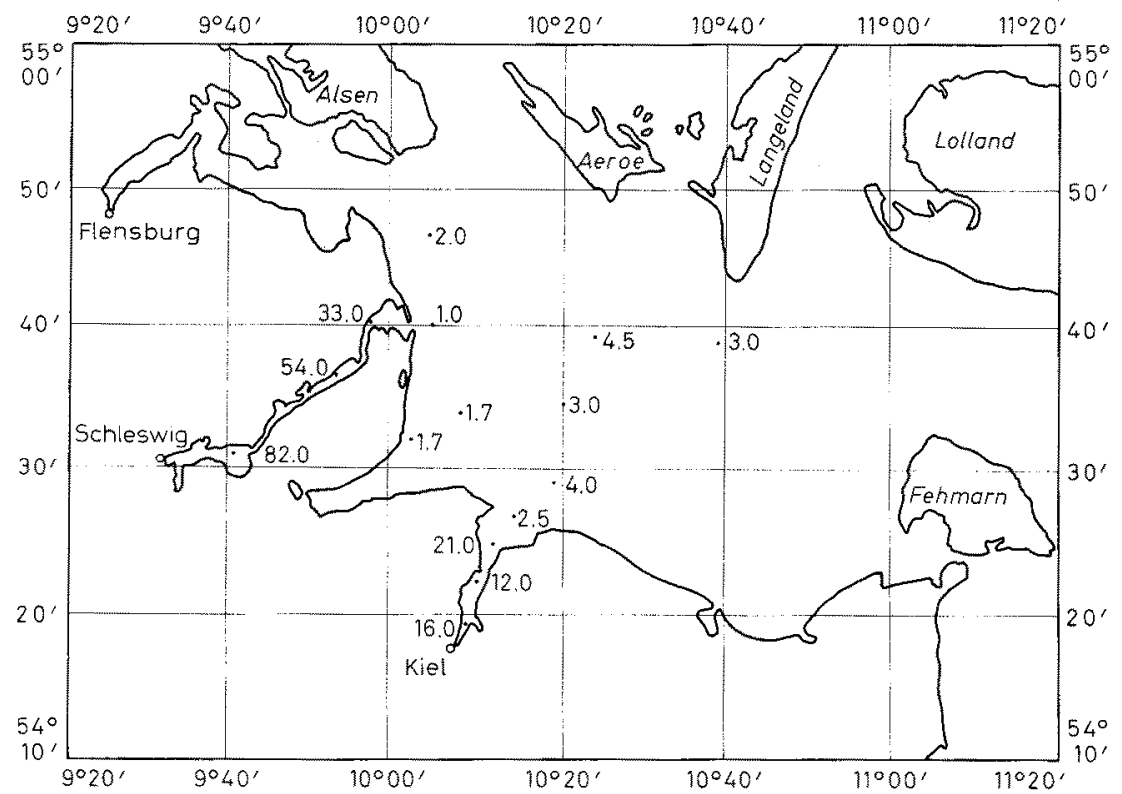

Abb. 5: Prozentualer Anteil der auf mit Süßwasser hergestelltem Pepton-Hefeextrakt-Medium wachsenden Bakterien an der Gesamtkeimzahl auf dem gleichen, jedoch mit Meerwasser (S $25 \%$ ) hergestellten Medium im Bereich der Kieler Bucht im April 1967

Die Umstellung der Bakterienflora von Populationen, die sich vorwiegend aus Süß- und Abwasserbakterien zusammensetzen auf solche, die hauptsächlich aus halophilen Meeresbakterien bestehen, verursacht eine Verlangsamung der Selbstreinigung des Wassers. Mit der Zunahme des Salzgehaltes im Brackwasserbereich des Elbe-Ästuars erfahren viele Süß- und Abwasserbakterien eine Hemmung, verlieren dann allmählich ihre Aktivität und sterben schließlich ab. Gleichzeitig nimmt zwar die Zahl der Brackwasser- und Meeresbakterien zu - aber die Stoff wechseltätigkeit vieler mariner Bakterien ist geringer und die Generationsdauer länger als bei entsprechenden Süßwassermikroben. Daher benötigt die Selbstreinigung von abwasserbelastetem Brack- oder Meerwasser die zwei- bis dreifache Zeit wie die von entsprechend belastetem Süßwasser unter sonst gleichen Bedingungen (Abb. 6). Der Abbau der von der Elbe mitgeführten Schmutzstoffe wird sich also mit dem Eintritt in die Brackwasserzone verlangsamen 
(vgl. Mann 1956). Hinzu kommt noch, daß die sommerlichen Wassertemperaturen im Mündungsbereich zeitweise niedriger sind als in den oberen Flußabschnitten, was dann zu einer weiteren Verlangsamung der Selbstreinigung führt.

Wenn auch der Anstieg des Salzgehaltes im Elbe-Ästuar entscheidend für die Anderung der Bakterienflora ist, so wird dieser Vorgang auch von der Höhe der Wassertemperatur beeinflußt, denn je höher die Temperatur ist, desto schneller erfolgt

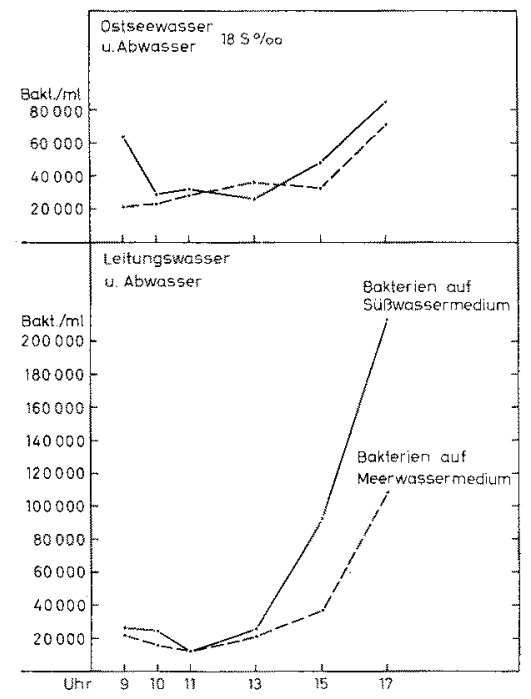

Abb. 6: Bakterienentwicklung nach Zugabe von $10 \mathrm{ml}$ städtischem Abwasser zu 1 l Ostseewasser (oben) und zu 11 Leitungswasser (unten). Nach anfänglicher Stagnation erfolgt der Anstieg der Keimzahlen im Leitungswasser erheblich schneller als im Ostseewasser

die Anderung der Bakterienflora zugunsten der halophilen Brackwasser- und Meeresbakterien. Das hat vor allem zwei Ursachen: einmal nimmt die hemmende Wirkung des Meerwassers auf Süßwasser- und Abwasserbakterien mit steigender Temperatur $\mathrm{zu}$ - und zum anderen erfolgt dann auch eine schnellere Vermehrung der halophilen Bakterien. Die hemmende Wirkung von Meerwasser auf nicht marine Bakterien beruht nur zum Teil auf dessen Salzgehalt, da die Hemmung stets größer als bei isotonen

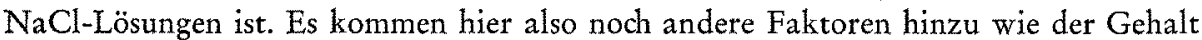
des Meerwassers an Antibiotika und Schwermetallen. Man spricht daher von einer bakteriziden Wirkung des Meerwassers. Auf diese ist u. a. auch das häufig beobachtete relativ schnelle Absterben von Escherichia coli und den meisten humanpathogenen Bakterien im Meerwasser zurückzuführen (Zobell 1946, Pramer, Carlucci \& SCarpino 1963, Jones 1963). Außerdem werden Bakteriophagen (ZoBELI 1946) und neuerdings auch kleine parasitische Bakterien, die dem von STOLP beschriebenen Bdellovibrio bacteriovorus ähnlich sind (MrTchell 1967), dafür verantwortlich gemacht. Doch dürften diese nur in stark verunreinigten Wasserkörpern eine Rolle spielen.

Die Höhe der Temperatur beeinflußt aber auch den Verunreinigungsgrad der südlichen Nordsee. So wird bei sommerlichen Wassertemperaturen infolge der höheren 
Aktivität der Mikroorganismen ein größerer Teil der Schmutzstoffe bereits in der Elbe bzw. in ihren Zuflüssen abgebaut, als das bei den niedrigen Wintertemperaturen der Fall ist. Daher erreichen im Sommer entsprechend weniger Schmutzstoffe die Nordsee. Hieraus ergibt sich, daß die Belastung unserer Küstengewässer bei gleichbleibender Einleitung in der kalten Jahreszeit größer ist als in den Sommermonaten, und es besteht die Gefahr, daß sich gewisse organische Giftstoffe (z. B. Detergentien, Phenole usw.) anreichern und vorübergehend eine kritische Konzentration erreichen. Besonders im zeitigen Frühjahr - in der Zeit von Ende März bis Mitte Mai - dürfte der Gehalt an solchen, an sich abbaufähigen Giftstoffen, das Maximum erreichen. Das darf vor allem bei der Einleitung von industriellen Abwässern nicht außer acht gelassen werden.

Im ganzen gesehen, haben die bakteriologischen Verhältnisse im Elbe-Ästuar einen sehr erheblichen Einfluß auf das Lebensgeschehen in der südlichen Nordsee - wenn dieser auch vorwiegend indirekter Natur ist. Von besonderer Bedeutung sind die mikrobiellen Umsetzungen im Brackwasserbereich der Flußmündungen, da von ihrer Intensität weitgehend der Verschmutzungsgrad der Nordsee abhängt. Unsere Kenntnisse vom biologischen Abbau der zahlreichen organischen Stoffe, die mit Abwässern und Abfällen in unsere Flüsse und Küstengewässer gelangen, sind immer noch völlig unzureichend, und am wenigsten wissen wir über die bakteriellen Prozesse im Brackwasser. Intensive Forschungen sind hier also besonders dringlich als Voraussetzung für die erstrebte sinnvolle Steuerung der Abwasser- und Abfallbelastung unserer Küstengewässer.

\section{ZUSAMMENFASSUNG}

1. Der Elbe und ihren Nebenflüssen werden an zahlreichen Orten städtische und industrielle Abwässer zugeführt und damit auch große Mengen von Bakterien und Nährstoffen. Von diesen gelangt ein Teil schließlich in die Nordsee und beeinflußt dort das Lebensgeschehen.

2. Der Bakteriengehalt des Elbewassers spiegelt sich in dem der Nordsee westlich von Helgoland wider. Die Zusammensetzung der Bakterienflora ist hier allerdings eine ganz andere. Denn die von der Elbe mitgeführten Süßwasser- und Abwasserbakterien werden großenteils im Mündungsgebiet zunächst durch Brackwasserbakterien und schließlich durch halophile Meeresbakterien ersetzt.

3. Die Anderung der Bakterienpopulationen in den halinen Zonen des Astuars wird von der Wassertemperatur beeinflußt; sie erfolgt um so schneller je höher die Temperatur ist.

4. Durch die Umstellung der Bakterienflora erfolgte die Selbstreinigung von abwasserbelastetem Brack- und Meerwasser langsamer als die von Süßwasser.

5. $\mathrm{Da}$ bei niedrigen Wassertemperaturen auch die Aktivität der meisten Bakterien abnimmt, kann es während des Winters zu einer Anreicherung von an sich abbaufähigen Schmutzstoffen in den Küstengewässern kommen.

Die Untersuchungen wurden von der Deutschen Forschungsgemeinschaft unterstützt. 


\section{ZITIERTE LITERATUR}

Caspers, H., 1959. Die Einteilung der Brackwasserregionen in einem Astuar. Archo Oceanogr. Limnol. 11 (Suppl.), 153-169.

GuNKEx, W., 1963. Daten und vorläufige Uberlegungen zur Bakterienverteilung in der Nordsee. Veröff. Inst. Meeresforsch. Bremerh. (Sonderbd) 1, 80-89.

- 1964. Einwirkungen des kalten Winters $1962 / 63$ auf die Bakterienpopulationen vor Helgoland. Helgoländer wiss. Meeresunters. 10, 246-256.

JonEs, G. E., 1963. Suppression of bacterial growth by sea water. In: Symposium on marine microbiology. Ed. by C. H. Oppenheimer. C. C. Thomas, Springfield, Ill., 572-579.

Lucht, F., 1964. Hydrographie des Elbe-Astuars. Arch. Hydrobiol. (Suppl. Bd) 29 (2), 1-96.

Mann, H., 1956. Aufarbeitung von Abwasser in Tideflüssen - dargestellt am Beispiel der Elbe. In: Uber Abwasserfragen im Küstengebiet. Deutscher Fischerei-Verband, Hamburg. (Arb. dt. Fisch.-Verb. 7, 8-16.)

Mrtchell, R., 1967. The effect of water movement on lysis of non-marine microorganisms by marine bacteria. Sarsia (im Druck).

Pramer, D., Carlucci, A. F. \& Scarpino, P. V., 1963. The bactericidal action of sea water. In: Symposium on marine microbiology. Ed. by C. H. Oppenheimer. C. C. Thomas, Springfield, Ill., 567-571.

Rheinheimer, G., 1964a. Einwirkungen des kalten Winters 1962/63 auf die Bakterienpopulation der Elbe. Helgoländer wiss. Meeresunters. 10, 257-262.

- 1964b. Beobachtungen über den Einfluß des strengen Winters 1962/63 auf das Bakterienleben eines Flusses. Kieler Meeresforsch. 20, 218-226.

- 1965. Mikrobiologische Untersuchungen in der Elbe zwischen Schnackenburg und Cuxhaven. Arch. Hydrobiol. (Suppl. Bd) 29 (2), 181-251.

- 1966. Einige Beobachtungen über den Einfluß von Ostseewasser auf limnische Bakterienpopulationen. Veröff. Inst. Meeresforsch. Bremerh. (Sonderbd) 2, 237-243.

WEYLAND, H., 1967. Beitrag zur quantitativen Verteilung mariner und "terrestrischer" Bakterien im Wasser und in Sedimenten der Deutschen Bucht. Helgoländer wiss. Meeresunters. $15,226-242$.

ZoBeLL, C. E., 1946. Marine microbiology; a monograph on hydrobacteriology. Chronica Botanica, Waltham, Mass., 240 pp.

\section{Diskussion im Anschluß an den Vortrag RHeinhermer}

PERSOONE: Have you investigated the relation of freshwater bacteria to marine bacteria in the sediments?

RHeinheImer: Wir haben im wesentlichen Untersuchungen im Wasser durchgeführt und bisher nur vereinzelt in Sedimenten, und zwar in der Strandzone der Ostsee. Aber Herr Dr. WeyLAND hat viel darüber gearbeitet. Vielleicht kann er Ihnen noch einiges sagen.

WeYland: Die quantitative Verteilung der Süß- und Meerwasserbakterien in den Sedimenten wurde in den Sedimenten der Außenweser bis $10 \mathrm{sm} \mathrm{NW}$ Helgoland untersucht. Dabei war der Anteil der Süßwasserbakterien auch in den Sedimenten relativ gering, d. h. etwa 5 bis 10\%. Dieser Anteil verändert sich auch $\mathrm{nicht}$ weiter seewärts im Sinne einer eventuellen Verminderung des Süßwasser-Bakterien-Anteils. Andererseits ist die absolute Zahl der Süßwasserbakterien in den marinen Sedimenten (NW Helgoland) noch recht hoch (z. B. 50000 Bakterien $/ \mathrm{cm}^{3}$ Sediment).

GILlbRicht: Ich wollte nur etwas sagen zu der organischen Belastung der Deutschen Bucht in der Gegend von Helgoland. Dort liegen die Werte für die organische Substanz im Winter oder im zeitigen Frühjahr höher als in den übrigen Monaten. Es zeigt sich zu dieser Zeit aber eindeutig, daß diese organische Belastung nicht mit dem Flußwasser hereinkommt. Wir haben während unserer Beobachtungszeit nie beobachten können, daß in der Gegend von Helgoland 
noch organische Verunreinigungen auftreten, die mit dem Flußwasser hereinkommen, sondern nur die Zersetzungsprodukte festgestellt. Das schließt jedoch nicht aus, daß einzelne, besonders bedenkliche Stoffe in geringer Menge noch vorhanden sind.

RHEINherMER: Das ist sehr interessant. Idh erwähnte ja, daß die Untersuchungen im Jahre 1963, während des sehr kalten Winters, in der Elbe außerordentlich hohe Bakterienzahlen brachten. Tatsächlich konnte Dr. Gunkes hier in Helgoland, 2 Monate später, ebenfalls extrem hohe Bakterienzahlen finden, die wir darauf zurïckgeführt haben. Wahrscheinlich besteht eben unter extremen Bedingungen dann doch diese Beziehung bis vor Helgoland, während sie sonst nur bis Feuerschiff Elbe 1 besteht.

WALLHÄUSER: Sie erwähnen im Zusammenhang mit der bakteriziden Wirkung des Meerwassers die Beteiligung von Antibiotika. Welche Vorstellungen hat man hier? Von vielen Antibiotika weiß man inzwischen, daß sie im Erdboden sehr rasch abgebaut werden. Ist die bakterizide Wirkung nicht vielmehr auf Spurenelemente, ich denke hierbei besonders an Jod und Kupfer, zurückzuführen?

RHeINHermer: Grundsätzlich glaube auch ich, daß vor allem Schwermetalle bzw, auch Schwermetallkomplexe eine große Rolle dabei spielen. Aber es darf nicht verkannt werden, daß zu bestimmten Jahreszeiten, vor allem im Zusammenhang mit dem Massenvorkommen bestimmter Planktonorganismen, doch Antibiotika abgegeben werden; man hat dies da und dort feststellen können. In Helgoland sind entsprechende Untersuchungen angelaufen. Es kommt dann tatsächlich durch diese Antibiotika zu einem signifikanten Rückgang der Bakterienzahlen. Man hat diesen Sachverhalt auch im Süßwasser festgestellt, vor allem von russischer Seite. So teilte KusNezow (1959) mit, daß in verschiedenen russischen Seen große Mengen von bestimmten Blaualgen auftreten, die Antibiotika abgeben und die Bakterienpopulation außerordentlich stark reduzieren.

SImpson: I was very interested in this paper, as our laboratory and the Water Pollution Laboratory of our Ministry of Technology are studying the fate of sewage bacteria in the sea. This is of importance in predicting the pollution of commercial molluse grounds from new sewage outfalls. I was interested in your observations that the death of coliforms is faster at higher temperatures, which we have also found. We are also working on the bactericidal effects of light which is found to be very great; there is little mortality in the dark. I would be interested to know whether comparable studies, including the bactericidal action of sea water, are being made in Germany.

RHEINHeImer: Es hat mich sehr interessiert, daß Sie im Grunde das gleiche wie wir feststellen konnten. $\mathrm{Zu}$ Ihrer Frage hinsichtlich des Lichteinflusses kann ich Ihnen sagen, daß von ENGEL in Hamburg entsprechende Untersuchungen durchgeführt wurden. Bislang allerdings nicht mit E. coli, aber mit einer Reihe von anderen Bakterien; bei diesen Untersuchungen konnte eindeutig festgestellt werden, daß eine schon relativ schwache Lichteinwirkung nichtpigmentierte Bakterien sehr schnell abzutöten vermag. Solche Bakterien die Carotinoide enthalten, sind bis zu einem gewissen Grad gegen diese Lichteinwirkung geschützt. Aus diesen Untersuchungen schließe ich, daß für $E$. coli ebenfalls eine starke Mortalität durch Lichteinwirkung gegeben ist. Untersuchungen über die Rolle der Antibiotika im allgemeinen wurden hier in Helgoland von Herrn GunKel begonnen.

Gunkel: Dr. Gandhr und ich haben den Verlauf der antimikrobiellen Potenzen des Seewassers im Jahreszyklus 1967 bei Verwendung mehrerer Testorganismen (Escherichia coli, Staphylococcus aureus und Serratia marinorubra) untersucht. Wir erhielten starke Unterschiede der $\mathrm{Ab}$ tötungskoeffizienten. Die Maxima der Abtötung ließen sich eindeutig mit den Spitzen von Phytoplanktonblüten korrelieren, und zwar einmal mit Phaeocystis und zum anderen mit Sceletonema. Von Phaeocystis ist bekannt, daß es die stark giftige Acrylsäure bildet. Wir vermuten, daß die Depressionen im Jahreszyklus der bakteriellen Keimzahlkurven des Seewassers wenigstens teilweise auf derartige antimikrobielle Substanzen zurïckgehen.

WeYLAND: Untersuchungen über die Verteilung von Escherichia coli-Typ I in Sedimenten des Weserästuars zeigten, daß in dem untersuchten Bereich (Bremerhaven - $50 \mathrm{~km}$ seewärts) keine 
Abhängigkeit des Vorkommens von Salzgehalt und Sedimentart bestand. In experimentellen Untersuchungen konnte in filtriertem Seewasser $E$. coli monatelang kontinuierlich wachsen. Eine Veränderung die den Nachweis dieses Bakteriums eventuell erschweren könnte, fand dabei nicht statt. Der Organismus hat auch nach sechsmonatiger Züchtung im Seewasser noch die typischen Coli-Eigenschaften.

RheINHermer: Dazu möchte ich noch eine kurze Bemerkung anschließen. Man muß dabei vielleicht noch berïcksichtigen, daß grundsätzlich Untersuchungen in Glasgefäßen beschränkter Größe zu anderen Ergebnissen führen, vor allem durch die von ZoBeıl (1946) hinreichend beschriebenen Absorptionsfähigkeiten des Glases. Insofern weiß ich nicht, ob man nun wirklich sagen kann, daß auf Grund dieser Ergebnisse, die wir auch bei anderen Bakterien gefunden haben, tatsächlich unbedingt biologische Grïnde im Meerwasser verantwortlich sind. Es ist durchaus möglich, daß geringste Veränderungen des Meerwassers durch Filtration und durch das Einbringen in Glasgefäße hier die Bakterizidie verändert haben. Es gibt darüber auch Untersuchungen von amerikanischen Kollegen, die Wasser autoklaviert und filtriert haben. Sie haben festgestellt, daß in jedem Fall eine Verminderung dieser Bakterizidie auftritt.

WaLlfäUSER: Um eine antibakterielle Wirkung zu erzielen sind doch hohe Konzentrationen möglich, so z. B. bei Tetracyclin $1 \mathrm{~g} / 10 \mathrm{~m}^{3}$. Glauben Sie, daß sich solche Konzentrationen im Meerwasser erzielen lassen? Bei Unterschreitung dieser Konzentration tritt keine Wachstumshemmung mehr ein, sondern im Gegenteil eine Fördernug. Adsorptive Vorgänge beschleunigen den Konzentrationsabfall.

Gunkel: Ich möchte Herrn Dr. WallhäUser widersprechen, daß die antibakteriellen Substanzen in sehr hoher Konzentration im Wasser vorliegen müssen. Sie reichern sich auf Partikeln an. Diese Partikel sind das eigentliche "Microenvironment", auf dem aud bakterielle Vermehrungen stattfinden. Diese werden dann beeinflußt. Im freien Wasser befinden sich, wenn es sehr nährstoffarm ist, kaum Bakterien. Den Nadhweis konnten wir sehr leicht erbringen. Durch Membranfiltration wurde der größte Teil der antimikrobiellen Wirkung entfernt.

Wallexëuser: Bei der Adsorption von Antibiotika an Partikel z. B. Ton, sind diese nicht mehr voll wirksam, keineswegs kann man hierbei von einer Konzentrierung im Sinne der antibiotischen Wirkung sprechen. Das kann man durch Adsorption von Antibiotika z. B. an Tierkohle oder Lehmpartikel beweisen.

Rheinhermer: Ich möchte nur noch ganz kurz auf eines hinweisen. Man muß bei diesen Dingen auch bedenken, daß das Meerwasser etwas völlig anderes ist als andere Lösungen und daß ein bakterizider Effekt für nichtmarine Bakterien schon durch den Salzgehalt gegeben ist. Dazu kommt noch die Wirkung von anderen Substanzen im Meerwasser. Das alles zusammen könnte nämlich zu einer verstärkten Empfindlichkeit gegenüber Antibiotika führen. Wir wissen darüber noch sehr wenig und es gibt auch in der Literatur einige widersprïchliche Angaben; ich glaube, man muß vor allem diese Besonderheit des Meerwassers bei derartigen Untersuchungen berücksichtigen. 